\title{
Satisfaction and expectations of patients with inflammatory bowel disease on biologic therapy: a multicenter study
}

\author{
Alessandra Guarinia, Silvia Biagini ${ }^{b}$, Antonella Capaldic, Daniela Carretto ${ }^{d}$, Anna De Angelise, \\ Salvatore ludicef, Giuseppina Martinog, Barbara Marzialih, Roberta Mattiolai, Cristina Ongarellij, \\ Francesca Maria Onidik, Manuela Prinzio', Reetha Puthiavettilm, Romina Sardin ${ }^{n}$, Elisa Schiavonio, \\ Rita Sinatora ${ }^{p}$, Angelo Zullo ${ }^{a}$
}

Nuovo Regina Margherita Hospital, Rome; Careggi Hospital, Florence; Santa Scolastica Hospital, Cassino; Cardinal Massaia Hospital, Asti; Fabrizio Spaziani Hospital, Frosinone; INRCA U. Sestilli Hospital, Ancona; IRCSS Casa Sollievo della Sofferenza Hospital, San Giovanni Rotondo; A. Murri Hospital, Fermo; Maria Vittoria Hospital, Turin; Sant’Andrea Hospital, La Spezia; Brotzu Hospital, Cagliari; Mauriziano Hospital, Turin; Tor Vergata University Hospital, Rome; San Camillo Hospital, Rome; Gemelli University Hospital, Rome; Pugliese Ciaccio Hospital, Catanzaro, Italy

\section{Abstract}

Background The satisfaction perceived by patients with chronic diseases affects clinical outcomes
and healthcare costs. Some patients with inflammatory bowel disease (IBD) develop a more severe
form requiring biologic therapy. We assessed the quality of care perceived by IBD patients in
dedicated centers.
Methods This prospective, cross-sectional, multicenter study enrolled consecutive IBD patients
who underwent biologic therapy in the participating centers. The nurses directly involved
in the management of these patients explained the rationale of the survey, provided a specific
questionnaire (CACHE), and collected data. The CACHE included 31 items structured in
6 domains: staff care, clinician care, center facilities, patient information, accessibility, and patient
support. Patients'satisfaction score for each domain ranged from 0 to $100 \%$.

Results Sixteen different Italian centers participated and a total of 450 patients were enrolled (283 with Crohn's disease and 167 with ulcerative colitis). The overall score was $82.2 \pm 19.6$, satisfaction with the clinicians care scoring the highest $(87.6 \pm 3.2)$ and the information provided to the patient scoring the lowest (70.7 \pm 7.9$)$. More specifically, it emerged that $5.2-19.5 \%$ of patients were unsatisfied with: 1) the communication between the IBD medical team and primary care physicians; 2) information received about the disease or patients' associations; and 3) the accessibility of the center.

Conclusion Although our data revealed an acceptably high rate of global satisfaction among IBD patients receiving biologic therapy, more effort should be made to improve patient information and communication between IBD teams, other specialists and primary care physicians.

Keywords Inflammatory bowel disease, Crohn's disease, ulcerative colitis, biologic therapy, patient satisfaction

Ann Gastroenterol 2017; 30 (1): 1-5

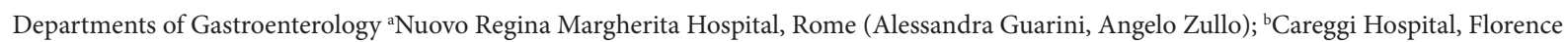
(Silvia Biagini); 'Santa Scolastica Hospital, Cassino (Antonella Capaldi); ${ }^{\mathrm{d} C a r d i n a l ~ M a s s a i a ~ H o s p i t a l, ~ A s t i ~(D a n i e l a ~ C a r r e t t o) ; ~}{ }^{\mathrm{e}}$ Fabrizio Spaziani

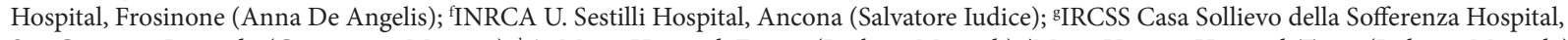
San Giovanni Rotondo (Giuseppina Martino); ${ }^{\text {A}}$ A. Murri Hospital, Fermo (Barbara Marziali); ${ }^{\mathrm{i}}$ Maria Vittoria Hospital, Turin (Roberta Mattiola);

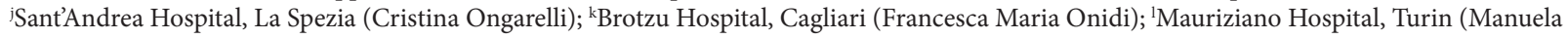

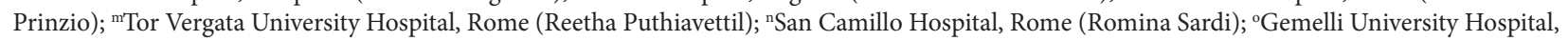
Rome (Elisa Schiavoni); pPugliese Ciaccio Hospital, Catanzaro (Rita Sinatora), Italy
\end{abstract}

Conflict of Interest: None

Correspondence to: Dr. Angelo Zullo, Gastroenterologia ed Endoscopia Digestiva, Ospedale Nuovo Regina Margherita, 30 Via Emilio Morosini, 00153 Rome, Italy, Tel.: +39 06 58446608, Fax: +39 06 58446533, e-mail: angelozullo66@yahoo.it

Received 25 August 2016; accepted 04 October 2016 published online 27 October 2016

DOI: https://doi.org/10.20524/aog.2016.0100 


\section{Introduction}

Inflammatory bowel disease (IBD) is a chronic condition, mainly represented by Crohn's disease (CD) and ulcerative colitis (UC) [1,2], diagnosed at a young age, having a considerable impact on the quality of life of both patients and their families, and causing healthcare resource consumption [3-5]. It is estimated that around $10-15 \%$ of IBD patients develop a more severe form of disease and need biologic therapy $[1,2,6,7]$. The management of this patient subgroup generally requires a multidisciplinary team, including different specialists, dedicated nurses, psychologists, and dieticians $[8,9]$.

As with other chronic diseases [10], the patient's satisfaction may play a role in the long-term management of IBD. This is particularly expected for IBD patients on biologic therapy, who will need close follow up in dedicated centers $[5,6]$. Therefore, assessing the quality of care perceived by IBD patients in dedicated centers is relevant from both clinical and healthcare resource consumption perspectives. The quality of care depends mainly on adequate healthcare facilities, information regarding the disease, helplines for patient-nurse or patient-physician relationships, and prompt access to visits or diagnostic tests when a disease flare-up occurs [8,9]. Consequently, some specific questionnaires have been developed to assess IBD patients' satisfaction with care [11-13].

Under the auspices of the ANOTE-ANIGEA (National Italian Association of Operators of Endoscopic Techniques - National Italian Association of Gastroenterology Nurses and Associates), we performed a cross-sectional, multicenter study to assess the quality of care perceived by IBD patients receiving biologic therapy in different Italian centers.

\section{Materials and methods}

\section{Survey design}

The rationale behind this survey was explained to nurses attending the ANOTE-ANIGEA National Congress that took place in May 2015 in Bologna, Italy. Only those nurses directly involved in the management of IBD patients on biologic therapy were asked to participate. Participant nurses received the protocol and the survey questionnaire when they checked in at the registration desk. The nurses involved were required to fully explain the rationale of the survey to those patients who were undergoing biologic therapy. Data were collected prospectively between 1 September and 30 November 2015. More specifically, in each center, the nurse provided each patient with the printed CACHE questionnaire [13], together with another sheet for the collection of demographic and clinical information. The nurse then collected the anonymized questionnaires completed by the patients who agreed to participate in the survey, and recorded the number of patients who declined participation. All questionnaires were mailed to a single center, where two investigators (AG and AZ) entered the data into a computerized spreadsheet for statistical evaluations.
Each patient provided written, informed consent to their participation in the study and the anonymous data analysis.

\section{Questionnaire}

To measure the quality of care perceived by IBD patients, we used the CACHE questionnaire [13], closely translated into Italian. This is a specific questionnaire, recently developed and validated [14], composed of a single sheet with 31 items structured in the following 6 domains: 1) staff care (10 items); 2) clinician care (5 items);3) center facilities (4 items); 4) patient information (5 items); 5) accessibility (4 items); and 6) patient support ( 3 items). For each item, the patients was required to choose one of 5 response options, consisting of "Totally agree", "Agree", "Neither agree nor disagree", "Disagree", and "Totally disagree". The following formula was used to calculate a score for each item: (real score - minimum score)/(maximum score - minimum score $) \times 100$. The final score was standardized to achieve a range from 0 (lowest level of satisfaction) to $100 \%$ (maximum satisfaction), for each item [14], the total representing the overall degree of patient satisfaction. To measure the frequency of disappointed patients, data were also analyzed taking into account the number of positive ("totally agree" and "agree") and negative ("totally disagree" and "disagree") responses for each domain. Those questionnaires missing $>10 \%$ of responses were considered as incomplete and were excluded from the analysis [13].

\section{Results}

A total of 16 different IBD centers participated in the survey, distributed throughout northern (4 centers), central (9 centers), and southern ( 3 centers) Italy, including 4 Universities and 12 General Hospitals. A total of 493 patients were invited, but 43 declined to participate. All questionnaires from the remaining $450(91.3 \%)$ patients were evaluable, the missing response rate being only $1.4 \%$ (range: $0-4.8 \%$ ). There were 283 patients with CD and 167 with UC, including 256 males and 194 females, with a mean age of $43.5 \pm 14.7$ years. Among the CD group, there were 127 (44.9\%) patients who had undergone previous surgical resection and 53 (18.7\%) with a perianal disease. The median number enrolled in the various centers was 25 patients (range: 5-92). The main characteristics of the patients are provided in Table 1.

The scores describing patients' satisfaction according to the 6 domains are reported in Table 2. The overall score was $82.2 \pm 19.6$, satisfaction with the clinician's care scoring the highest $(87.6 \pm 3.2)$ and the information provided to the patient scoring the lowest (70.7 \pm 7.9$)$. More specifically, the mean satisfaction score exceeded 85 only for the staff and clinician care domains, whilst it was $<80$ for both center facilities and patient information. No difference in the overall satisfaction score was noted between CD and UC patients (80.1 \pm 23.4 vs. $82.8 \pm 22.6)$, between males and females (81.4 \pm 22.5 vs. 
Table 1 Demographic and clinical characteristics of patients with Crohn's disease (CD) or ulcerative colitis (UC)

\begin{tabular}{lccc}
\hline Characteristics & $\mathrm{CD}(\mathrm{n}=283)$ & $\mathrm{UC}(\mathrm{n}=167)$ & Overall $(\mathrm{n}=450)$ \\
\hline Male/female & $162 / 121$ & $94 / 73$ & $256 / 194$ \\
\hline Age (mean \pm SD; years) & $42.8 \pm 11.3$ & & $43.5 \pm 14.7$ \\
Education level (\%) & & $31(18.6)$ & $95(21.1)$ \\
Tertiary & $64(22.6)$ & $79(47.3)$ & $219(48.7)$ \\
Secondary & $140(49.5)$ & $34(20.3)$ & $130(28.9)$ \\
Primary & $96(33.9)$ & 4 & $6(1.3)$ \\
No education & 2 & & $285(63.3)$ \\
Employment status (\%) & & $100(59.9)$ & $44(9.8)$ \\
Employed & $185(65.4)$ & $18(10.8)$ & $11(2.4)$ \\
Retired & $26(9.2)$ & $4(2.4)$ & $14(3.2)$ \\
Student & $7(2.5)$ & $4(2.4)$ & $91(20.2)$ \\
Housekeeper & $10(3.5)$ & $28(16.8)$ & $5(1.1)$ \\
$\quad$ Unemployed & $63(22.2)$ & $3(0.2)$ & $11.7 \pm 1.3$ \\
Work disabled & $2(0.1)$ & $11.1 \pm 0.9$ & $351 / 98$ \\
Disease duration (Mean \pm SD; yrs) & $12.1 \pm 1.8$ & $143 / 24$ & $130(29)$ \\
Biologic therapy (intravenous/subcutaneous) & $208 / 75$ & $31(18)$ & $79(17.5)$ \\
Current smoking (\%) & $99(35)$ & $33(20)$ & \\
Concomitant diseases (\%) & $46(16)$ & & \\
\hline
\end{tabular}

Table 2 Mean values of patients' satisfaction according to the 6 domains

\begin{tabular}{lc}
\hline Domain & Mean \pm SD \\
\hline Staff care & $85.2 \pm 6.2$ \\
Clinician care & $87.6 \pm 3.2$ \\
Center facilities & $79.9 \pm 1.6$ \\
Patient information & $70.7 \pm 7.9$ \\
Accessibility & $83.8 \pm 3.7$ \\
Patient support & $82.8 \pm 3.6$ \\
\hline
\end{tabular}

$83.3 \pm 21.9)$, or between those receiving intravenous or subcutaneous biologic therapy $(82.3 \pm 23.5$ vs. $81.7 \pm 21.8)$.

By analyzing the frequencies of responses, we found that patients gave negative scores ("totally disagree" and "disagree" quoted together) on as many as $8(25.1 \%)$ of 31 items (Table 3 ). In total, more than 5\% (range: $5.2-19.5 \%$ ) of patients were unsatisfied with the communication between the medical team and primary care physicians, information received about the disease or patients' associations, and the accessibility of the center.

\section{Discussion}

Quality of care assessment in patients with chronic diseases has received increasing attention in the last decade, and there has been an increasing understanding among health carers that an improvement in patient satisfaction is associated with better health outcomes, as for diabetes and hypertension [10]. Indeed, better quality in the healthcare provided to patients improves clinical outcomes and reduces overall costs $[15,16]$. IBD is chronic and some of these patients are faced with various challenges, such as recurrent hospitalizations, surgical interventions, definitive stoma, occurrence of extra-intestinal manifestations, and long-lasting biologic therapy [1-8,17]. The degree of patient satisfaction has been found to affect the quality of life of IBD patients, as well as their adherence to both medical treatment and other aspects of care [18-20]. Moreover, the United Kingdom IBD Standards Group emphasizes the importance of maintaining patient-centered care [21]. Hence, assessing IBD patients' perceived degree of satisfaction with global care is important.

In this large, multicenter survey we used the CACHE questionnaire to measure patient satisfaction in IBD patients undergoing ongoing biologic therapy $[13,14]$. Among the possible tools, we chose this questionnaire because, compared to other questionnaires such as QUOTE-IBD, patients can complete it more easily and quickly $[11,13]$. Our data showed that the global satisfaction rate in IBD patients receiving biologic therapy is acceptably high (82.2\%). However, such a value would also indicate that the quality of care perceived by this subgroup of IBD patients could be further improved, at least in some fields. Interestingly, we observed that the domain concerning patient information achieved the lowest satisfaction score $(70.7 \pm 7.9)$. More specifically, we found that as many as $19.5 \%$ of patients were not satisfied with the IBD information 
Table 3 Items with a frequency of disagreement higher than 5\%

\begin{tabular}{|c|c|}
\hline Domain & $\%$ \\
\hline \multicolumn{2}{|l|}{ Staff care (1 of 10 items) } \\
\hline $\begin{array}{l}\text { There is good coordination and communication } \\
\text { between my medical team and other specialists and/or } \\
\text { primary care }\end{array}$ & 13.1 \\
\hline \multicolumn{2}{|l|}{ Center facilities ( 3 of 4 items) } \\
\hline $\begin{array}{l}\text { The center I go to have my condition treated is } \\
\text { well-located and easily accessible }\end{array}$ & 7.6 \\
\hline $\begin{array}{l}\text { The bathrooms in the center are adequate and } \\
\text { accessible }\end{array}$ & 6.4 \\
\hline $\begin{array}{l}\text { The center where they administer my medication has } \\
\text { the necessary resources and facilities }\end{array}$ & 5.2 \\
\hline \multicolumn{2}{|l|}{ Patient information ( 3 of 5 items) } \\
\hline $\begin{array}{l}\text { At the hospital where I get treatment for my bowel } \\
\text { disease, I can get information about my disease } \\
\text { through brochures, information campaigns, etc. }\end{array}$ & 19.5 \\
\hline $\begin{array}{l}\text { I have been informed about how to contact patients' } \\
\text { associations for people with intestinal problems like } \\
\text { mine }\end{array}$ & 18.9 \\
\hline $\begin{array}{l}\text { I get advice and guidance about nutrition, daily } \\
\text { activities, exercise, etc., which I have to follow because } \\
\text { of my bowel disease }\end{array}$ & 5.5 \\
\hline \multicolumn{2}{|l|}{ Accessibility (1 of 4 items) } \\
\hline $\begin{array}{l}\text { In the center I go to for treatment, I can be attended over } \\
\text { the phone }\end{array}$ & 5.2 \\
\hline
\end{tabular}

they received through brochures and books, and from healthcare staff. In another study involving 290 Spanish patients with IBD, which used the same questionnaire (CACHE), the patient information score was the lowest $(68.5 \pm 18)$ [14]. Likewise, using a different questionnaire (QUOTE-IBD), the received information was judged unsatisfactory by $28 \%$ of patients in a previous Italian study performed between April 2010 and February 2011 [22], and by 45\% of 162 Dutch IBD patients in 2001 [11]. Since adequate information has a positive impact on quality of life, more effort should be made to improve information for IBD patients [23]. Indeed, a better knowledge about the disease is associated with emotional adjustment to living with IBD $[4,24,25]$. Notably, it has recently been observed that information received from clinical staff (gastroenterologists, dedicated nurses) is much more important for IBD patients than that obtained from the internet [26]. Indeed, IBD patients would rather receive additional information on treatment, clinical manifestations, cancer, and mortality risks in face-toface interviews [26]. Improved patient information could also affect smoking habits. It was astonishing to note that as many as $35 \%$ of our patients with $\mathrm{CD}$ who were receiving biologic therapy were current smokers, despite the deleterious effects of smoking in these patients [27].

Another relevant finding of our survey related to the patients' satisfaction with the healthcare staff. Although the global score for this domain was $85.2 \pm 6.2$, a value very similar to the $86.2 \pm 11.8$ observed in a Spanish study [14],

\section{Summary Box}

\section{What is already known:}

- There is increasing evidence that the satisfaction perceived by patients with inflammatory bowel disease (IBD) affects clinical outcomes and healthcare costs

- This is particularly expected for IBD patients on biologic therapy, who will need close follow up in dedicated centers

- The CACHE questionnaire is a specific questionnaire, recently developed and validated, to measure IBD patients' satisfaction

\section{What the new findings are:}

- This Italian multicenter survey showed that the overall satisfaction score was acceptably high. However, patient information received the lowest score

- Improved provision of information for IBD patients about biologic therapy, as well as communication between IBD teams, other specialists and primary care physicians need to be implemented

we found that as many as $13.1 \%$ of patients were unsatisfied with the communication between the medical team and other specialists and/or primary care physicians. Such a finding would suggest that the presence of a multidisciplinary IBD team including different physicians (gastroenterologist, surgeon, rheumatologist, dermatologist), dedicated nurses, dieticians and psychologists, should be implemented, as has been widely suggested [1-9,28]. Moreover, appropriate communication between the IBD team at the dedicated center and the general practitioner should not be neglected. Indeed, it has been found that the general practitioner as an information source is preferred by as many as $83 \%$ of IBD patients [26].

A limitation of our study was that the CACHE questionnaire, previously developed in Spain, has not been validated in Italy.

In conclusion, our survey found an acceptably high rate of global satisfaction in IBD patients receiving biologic therapy. However, further effort should be made to improve patient information and communication between IBD teams, other specialists and primary care physicians.

\section{References}

1. Dignass A, Eliakim R, Magro F, et al. Second European evidencebased consensus on the diagnosis and management of ulcerative colitis part 1: definitions and diagnosis. J Crohns Colitis 2012;6:965-990.

2. Van Assche G, Dignass A, Bokemeyer B, et al; European Crohn's 
and Colitis Organisation. Second European evidence-based consensus on the diagnosis and management of ulcerative colitis part 3: special situations. J Crohns Colitis 2013;7:1-33.

3. Casellas F, López-Vivancos J, Vergara M, Malagelada J. Impact of inflammatory bowel disease on health-related quality of life. Dig Dis 1999;17:208-218.

4. Taft TH, Keefer L. A systematic review of disease-related stigmatization in patients living with inflammatory bowel disease. Clin Exp Gastroenterol 2016;9:49-58.

5. Cohen RD. The pharmacoeconomics of biologic therapy for IBD. Nat Rev Gastroenterol Hepatol 2010;7:103-109.

6. Orlando A, Armuzzi A, Papi C, et al; Italian Group for the study of Inflammatory Bowel Disease. The Italian Society of Gastroenterology (SIGE) and the Italian Group for the study of Inflammatory Bowel Disease (IG-IBD) Clinical Practice Guidelines: The use of tumor necrosis factor-alpha antagonist therapy in inflammatory bowel disease. Dig Liver Dis 2011;43:1-20.

7. Annese V, Vecchi M; Italian Group for the Study of IBD (IG-IBD). Use of biosimilars in inflammatory bowel disease: Statements of the Italian Group for Inflammatory Bowel Disease. Dig Liver Dis 2014;46:963-968.

8. Van Assche G, Dignass A, Reinisch W, et al; European Crohn's and Colitis Organisation (ECCO). The second European evidencebased Consensus on the diagnosis and management of Crohn's disease: Special situations. J Crohns Colitis 2010;4:63-101.

9. O'Connor M, Bager P, Duncan J, et al. N-ECCO Consensus statements on the European nursing roles in caring for patients with Crohn's disease or ulcerative colitis. J Crohns Colitis 2013;7:744-764.

10. Kaplan SH, Greenfield S, Ware JE Jr. Assessing the effects of physician-patient interactions on the outcomes of chronic disease. Med Care 1989;27:S110-S127.

11. van der Eijk I, Sixma H, Smeets T, et al; European Collaborative Study Group on IBD. Quality of health care in inflammatory bowel disease: development of a reliable questionnaire (QUOTE-IBD) and first results. Am J Gastroenterol 2001;96:3329-3336.

12. Sadlo A, Altevers J, Peplies J, et al. Measuring satisfaction with health care in young persons with inflammatory bowel diseasean instrument development and validation study. BMC Health Serv Res 2014; 14:97.

13. Casellas F, Ginard D, Vera I, Torrejón A; GETECCU. Development and testing of a new instrument to measure patient satisfaction with health care in inflammatory bowel disease: the CACHE questionnaire. Inflamm Bowel Dis 2013;19:559-568.

14. Casellas F, Vera I, Ginard D, Torrejón A; Grupo Español de Trabajo En Enfermedad de Crohn Y Colitis Ulcerosa Geteccu. Inflammatory bowel disease patient's satisfaction with healthcare services received. Physicians' and nurses' perceptions. Rev Esp
Enferm Dig 2013;105:385-391.

15. Fenton JJ, Jerant AF, Bertakis KD, Franks P. The cost of satisfaction: a national study of patient satisfaction, health care utilization, expenditures, and mortality. Arch Intern Med 2012;172:405-411.

16. Jerant A, Fenton JJ, Bertakis KD, Franks P. Satisfaction with health care providers and preventive care adherence: a national study. Med Care 2014;52:78-85.

17. Csontos A, Molnár A, Piri Z, et al. The effect of anti-TNFa induction therapy on the nutritional status and dietary intake in inflammatory bowel disease. J Gastrointestin Liver Dis 2016;25:49-56.

18. van der Eijk I, Stockbrügger R, Russel M. Influence of quality of care on quality of life in inflammatory bowel disease (IBD): literature review and studies planned. Eur J Intern Med 2000;11:228-234.

19. Bager P, Julsgaard M, Vestergaard T, Christensen LA, Dahlerup JF. Adherence and quality of care in IBD. Scand J Gastroenterol 2016;51:1326-1331.

20. Principi M, Losurdo G, La Fortezza RF, et al. Does infliximab short infusion have a beneficial impact on the quality of life in patients with inflammatory bowel diseases? A single centre prospective evaluation. J Gastrointestin Liver Dis 2015;24:165-170.

21. Arnott I, Bloom S, Edwards C, et al. IBD Standards Working Group. Quality care: service standards for the healthcare of people who have inflammatory bowel disease (IBD), 2013.

22. Bortoli A, Daperno M, Kohn A, et al; Italian Group for the study of Inflammatory Bowel Disease (IG-IBD). Patient and physician views on the quality of care in inflammatory bowel disease: results from SOLUTION-1, a prospective IG-IBD study. J Crohns Colitis 2014;8:1642-1652.

23. Casellas F, López-Vivancos J, Badia X, Vilaseca J, Malagelada JR. Impact of surgery for 'Crohn's disease on health-related quality of life. Am J Gastroenterol 2000;95:177-182.

24. Casellas F, Fontanet G, Borruel N, Malagelada JR. The opinion of patients with inflammatory bowel disease on healthcare received. Rev Esp Enferm Dig 2004;96:174-184.

25. de Boer AG, Sprangers MA, Bartelsman JF, de Haes HC. Predictors of health care utilization in patients with inflammatory bowel disease: a longitudinal study. Eur J Gastroenterol Hepatol 1998;10:783-789.

26. Catalán-Serra I, Huguet-Malavés JM, Mínguez M, et al. Information resources used by patients with inflammatory bowel disease: Satisfaction, expectations and information gaps. Gastroenterol Hepatol 2015;38:355-363.

27. Coward S, Heitman SJ, Clement F, et al. Funding a smoking cessation program for Crohn's disease: an economic evaluation. Am J Gastroenterol 2015;110:368-377.

28. Conigliaro P, Chimenti MS, Ascolani M, et al. Impact of a multidisciplinary approach in enteropathic spondyloarthritis patients. Autoimmun Rev 2016;15:184-190. 